\title{
Effect of heat treatment on corrosion behavior of low pressure sand cast Mg-10Gd-3Y-0.5Zr alloys
}

\author{
Qian-qian Wu', ${ }^{1,}$ * Guang-ling Wei ${ }^{1}$, Guo-hua Wu', Wen-cai Liu', Tian-peng Xuan ${ }^{\mathbf{2}}$ and Wen-jiang Ding ${ }^{\mathbf{1}}$ \\ 1. National Engineering Research Center of Light Alloy Net Forming and State Key Laboratory of Metal Matrix Composites, School of Materials \\ Science and Engineering, Shanghai Jiao Tong University, Shanghai 200240, China \\ 2. School of Materials Science and Engineering, Hefei University of Technology, Anhui 230009, China
}

\begin{abstract}
The corrosion behaviors of low-pressure sand cast Mg-10Gd-3Y-0.5Zr (wt.\%) alloys in as-cast, solution treated (T4) and aged (T6) conditions were studied by means of immersion test and electrochemical measurements in $5 \mathrm{wt} . \% \mathrm{NaCl}$ solution saturated with $\mathrm{Mg}(\mathrm{OH})_{2}$. It was observed that the corrosion rate in the T4 condition was lower than that of the as-cast and T6 conditions by both sand casting and permanent mold casting with the same order of as-cast $>\mathrm{T} 6>\mathrm{T} 4$; while the corrosion resistance of the permanent mold casting is superior to the sand casting. The morphologies of the corrosion products are similar porous structures consisting of tiny erect flakes perpendicular to the corroded surface of the alloy, irrespective of the heat treatment conditions. Especially, the corrosion film in T4 condition is more compact than that in the other two conditions. In addition, the severer corrosion happening to the as-cast condition is correlated with the galvanic corrosion between the matrix and the eutectic compounds; while improved corrosion resistance for the T4 and T6 conditions is ascribed to the dissolution of the secondary eutectic compounds. The measured corrosion current densities of Mg-10Gd-3Y-0.5Zr alloys in as-cast, $\mathrm{T} 4$, and $\mathrm{T} 6$ conditions are $36 \mu \mathrm{A}^{\cdot} \mathrm{cm}^{-2}, 10 \mu \mathrm{A} \cdot \mathrm{cm}^{-2}$, and $33 \mu \mathrm{A} \cdot \mathrm{cm}^{-2}$, respectively. The proposed equivalent circuit $\left[R_{s}\left(C E_{1}\left(R_{t}\left(R_{f} C P E_{2}\right)\right)\right]\right.$ by Zview software matches well with the tested electrochemical impedance spectra (EIS) data.
\end{abstract}

Key words: sand casting; Mg-10Gd-3Y-0.5Zr; heat treatment; corrosion
CLC numbers: TG146.22
Document code: A
Article ID: 1672-6421/2016 04-276-08

$\mathrm{M}$ agnesium alloys containing heavy rare earth elements are of high strength and low density, which makes them very attractive as structural materials in applications, for example, aircraft and space machinery, and ground transport including racing automobiles, where weight saving is of great importance ${ }^{[1-3]}$. It has been reported that the recently developed $\mathrm{Mg}-\mathrm{Gd}-\mathrm{Y}-\mathrm{Zr}$ alloys such as $\mathrm{Mg}-10 \mathrm{Gd}-3 \mathrm{Y}-0.5 \mathrm{Zr}$ alloy show considerable precipitation hardening, leading to improved specific strength at both room and elevated temperatures, and better creep resistance than conventional $\mathrm{Al}$ and $\mathrm{Mg}$ alloys ${ }^{[4-6]}$. According to the literature ${ }^{[7,8]}, \mathrm{Mg}-10 \mathrm{Gd}$ $3 \mathrm{Y}-0.5 \mathrm{Zr}$ alloy is employed to produce complicated

\section{*Guang-ling Wei}

Female, Master's degree, Assistant Researcher. Research direction: surface treatment of magnesium and aluminum alloys.

E-mail:weigl010@sjtu.edu.cn

Received: 2016-01-14; Accepted: 2016-03-07 components by low-pressure sand casting (LPSC) in production for the combination of higher strength and higher ductility than other Mg-Gd-Y alloys. Moreover, LPSC is an appropriate technique to produce $\mathrm{Mg}$ components, especially those with thin-walls $(2-5 \mathrm{~mm})$ and complex geometry ${ }^{[9]}$. In the past few years, many investigations related to the microstructure, mechanical properties and corrosion behaviors of the Mg-10Gd$3 \mathrm{Y}-0.5 \mathrm{Zr}$ alloys cast in metal molds have been reported. However, there are few research reports about the sandmold casting magnesium alloys, especially for the corrosion behaviors.

It is well known that an alloy produced by lowpressure sand-casting process has a different microstructure (as precipitation sequence, phase type and composition, grain size etc.) and mechanical behaviors compared to an alloy produced by permanent mold casting process due to the different cooling rate ${ }^{[10,11]}$, which will make the different casting alloys show different corrosion behaviors. Many extensive 
investigations and evaluations about the corrosion behavior of magnesium alloys have been carried out on the permanent mold casting. Sun et al. ${ }^{[6]}$ studied the effect of $\mathrm{Zr}$ addition on the microstructure, mechanical properties and corrosion resistance of permanent mold cast Mg-10Gd-3Y alloy. Chang et al. ${ }^{[12]}$ reported the corrosion behaviors for metal-cast $\mathrm{Mg}-x \mathrm{Gd}-3 \mathrm{Y}-0.4 \mathrm{Zr}$ alloys in a peak-aged condition. Wang et al. ${ }^{[13]}$ studied the mechanical and corrosion properties of metal-cast Mg-10Gd-3Y-0.5Zr alloy purified by flux containing $\mathrm{GdCl}_{3}$ additions. However, the literature about the corrosion behaviors of the LPSC Mg-10Gd$3 \mathrm{Y}-0.5 \mathrm{Zr}$ alloy is not yet available.

The Mg-Gd-Y alloys produced by LPSC are becoming more attractive to automotive structural applications in industry. However, the widespread application is largely limited by the poor corrosion resistance of the Mg-Gd-Y alloys. Because the structural components are usually used under the condition of heat treatment, it is essential to study the corrosion behaviors of the heat treated sand casting Mg-Gd-Y alloys. In the present work, the corrosion behaviors of low-pressure sand-cast Mg10Gd-3Y-0.5Zr alloys under different heat treatment conditions including as-cast, solid solution state (T4), and solid solution plus aged state (T6) were investigated systematically.

\section{Experimental procedures}

\subsection{Specimen preparation}

The material used in this study is the alloy with the nominal composition of Mg-10Gd-3Y-0.5Zr (wt.\%). A low-pressure sand casting process was employed and the schematic diagram of the LPSC equipped with resin-bonded sand mold is shown in Fig. 1. The magnesium ingot ( $\geqslant 99.9$ wt.\%) was melted in the steel crucible under the mixed atmosphere of $\mathrm{CO}_{2}$ and $\mathrm{SF}_{6}$ with the ratio of $100: 1 . \mathrm{Mg}-25 \% \mathrm{Y}$ and $\mathrm{Mg}-25 \% \mathrm{Gd}$ master alloys were added when the temperature reached $740{ }^{\circ} \mathrm{C}$, followed by manual stirring for $2 \mathrm{~min}$. After being purified by $1.5 \% \mathrm{JDMJ}$ flux $\left(\mathrm{MgCl}_{2}\right.$ : 40-50 wt.\%; KCl: 15-25 wt.\%; NaCl:15-20 wt.\%), the melt was subsequently held at $780{ }^{\circ} \mathrm{C}$ for $40 \mathrm{~min}$, and then the $150{ }^{\circ} \mathrm{C}$ preheated $\mathrm{Mg}-30 \% \mathrm{Zr}$ master alloy was added to the melt. Finally, the melt was poured into the no-bake resin sand mold and then cast into cylindrical bars as shown in Fig. 2. The actual chemical composition was determined to be Mg-9.18Gd-2.93 Y-0.46Zr (wt.\%) by using an inductively coupled plasma analyzer (ICP, Perkin Elmer, Plasma-400). Based on the experimental results, $\mathrm{T} 4$ solid solution treatment $\left(525{ }^{\circ} \mathrm{C} \times 12 \mathrm{~h}\right)$, T6 heat treatment

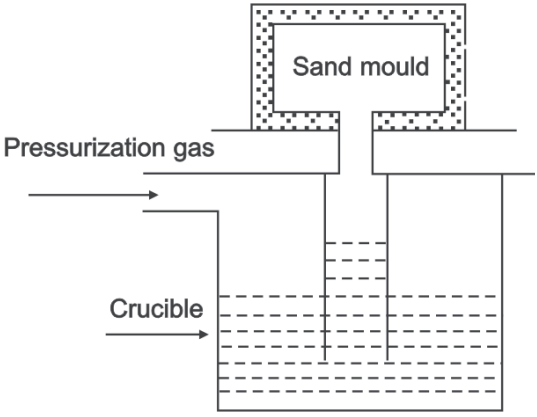

Fig. 1: Principle diagram of LPSC

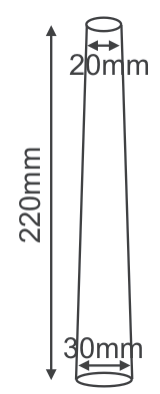

Fig. 2: Low-pressure casting bar (solid solution treatment followed by artificial aging, $525{ }^{\circ} \mathrm{C} \times$ $12 \mathrm{~h}+250^{\circ} \mathrm{C} \times 10 \mathrm{~h}$ ) were applied to some of the cast ingots. After heat treatment, the specimens were cut into $\Phi 30 \mathrm{~mm} \times 5$ $\mathrm{mm}$ rods for the immersion tests and $2 \mathrm{~mm} \times 2 \mathrm{~mm} \times 5 \mathrm{~mm}$ for electrochemical measurements from the casting bars.

\subsection{Immersion test and electrochemical measurements}

The immersion test was conducted in $5 \mathrm{wt} . \% \mathrm{NaCl}$ (analytical reagent) aqueous solution. Before the immersion test, the specimens were ground on $\mathrm{SiC}$ waterproof abrasive papers and then polished until no scratches were visible, followed by washing with distilled water and subsequently dried in warm flowing air. After air drying, the specimens for immersion test were weighed for the initial weight. During the immersion test, the specimens were tied by a fishing line in $5 \mathrm{wt} . \% \mathrm{NaCl}$ solution for 3 days. Afterwards, the specimens were immersed into the $200 \mathrm{~g} \cdot \mathrm{L}^{-1}$ chromate acid solution with $10 \mathrm{~g} \cdot \mathrm{L}^{-1}$ silver nitrate at $35-40{ }^{\circ} \mathrm{C}$ for $7 \mathrm{~min}$ in order to remove the corrosion products on the surface. The change in mass of each specimen divided by the corrosion time and exposed surface area was defined as the weight loss rate.

The electrochemical measurements were performed in a threeelectrode corrosion cell filled with $5 \mathrm{wt} . \% \mathrm{NaCl}$ solution saturated with $\mathrm{Mg}(\mathrm{OH})_{2}$. The electrochemical cell was employed with graphite as the counter electrode, saturated calomel electrode (SCE) as the reference electrode, and the exposed surface of the specimens as the working electrode. All the tests were conducted by using a PARSTAT 2273 electrochemical test system. Open circuit potentials (EOC) were initiated immediately after the specimens were immersed in the solution and lasted for 3,600 s for each sample. The electrochemical impedance spectra (EIS) were measured at the moment that the open circuit potential measurement finished. The frequencies of EIS measurement were set from $100 \mathrm{kHz}$ to $100 \mathrm{MHz}$, meanwhile, the alternating current (AC) amplitude was $10 \mathrm{mV}$. The polarization curves measurements were performed from a cathodic potential of -250 $\mathrm{mV}$ relative to EOC and stopped at an anodic potential when the anodic current increased dramatically. The scanning rate was 1 $\mathrm{mV} \cdot \mathrm{s}^{-1}$. More than three samples of all the tests were used for each material separately to assure the reproduction of the data.

\subsection{Microstructure and phase analyses}

The metallographic structures of the tested Mg-10Gd-3Y-0.5Zr alloys were obtained using optical microscopy (OM). Before the metallographic structure observation, the specimens were polished until no scratches were visible on the surface and afterwards etched in 4vol.\% nitric acid alcohol solution. In addition, the morphologies of the corrosion products, the cross sectional images and the corroded surface after removal of the corrosion products were determined by field emission scanning electron microscopy (FE-SEM).

The phase constituent of the corrosion products was analyzed by X-ray diffraction (XRD) on a D/max $2550 \mathrm{~V}$ diffractometer with $\mathrm{Cu}-\mathrm{K}_{\alpha}$ radiation. The software used to analyze the XRD data was Jade 5.0. 


\section{Results and discussion}

\subsection{Microstructures}

Figure 3 shows the microstructures of the low-pressure sandcast Mg-10Gd-3Y-0.5Zr alloys in as-cast, T4 and T6 conditions. It can be seen that the microstructure of the as-cast condition (Fig. 3a) mainly consists of equiaxed $\alpha-\mathrm{Mg}$ and the eutectic compounds $\left[\mathrm{Mg}_{24}(\mathrm{Gd}, \mathrm{Y})_{5}\right.$ phase $]$ distributing along the grain boundries, mostly at the triple points, while that of the T4 condition (Fig. $3 b$ ) contains $\alpha-M g$ matrix and some cuboidshaped particles distributed along grain boundaries and inside the grains. The microstructure of T6 condition (Fig. 3c) is composed of $\alpha-\mathrm{Mg}$ matrix, dark cuboid-shaped phase and a high fraction of fine particles phase $\left[\beta^{\prime}-\mathrm{Mg}_{5}(\mathrm{Gd}, \mathrm{Y})\right]$, which are consistent with the results of Ref. [11-14]. During the solution treatment, Gd and $\mathrm{Y}$ elements dissloved into the matrix and formed supersaturated solid solution. Furthermore, the cuboid-shaped phase is a compound with high content of rare earth elements and exhibiting face-centered cubic structure ${ }^{[15,16]}$. This phase could be seen clearly after the solution treatment and continued to exist in the subsequent aging. The Zr-rich zones appeared to be obvious in the $\mathrm{T} 6$ condition.
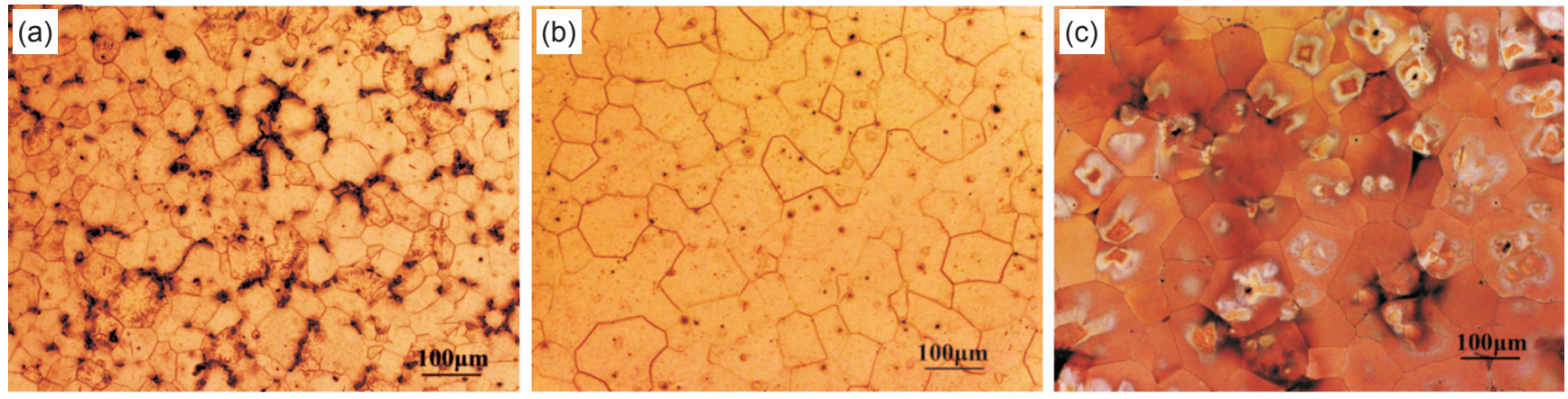

Fig. 3: Microstructure of Mg-10Gd-3Y-0.5Zr alloys in: (a) as-cast, (b) T4, (c) T6

In addition, the permanent mold casting results reported by Peng et al. ${ }^{[17]}$ were employed to compare with the sand casting. Although both the sand-cast and metal-cast alloys have similar microstructure, the grain sizes and the volume fraction of secondary phases are different for the different cooling rates in the same heat treatment conditions. The average grain sizes of sand-cast and metal-cast alloys are shown in Table 1. Generally, the average grain sizes of the sand-cast Mg-10Gd-3 Y-0.5Zr alloy are coarser than that of metal-cast alloys, but the difference between T4 and T6 conditions is relatively small.

Table 1: Average grain sizes of sand-casting and permanent mold casting Mg-10Gd-3Y-0.5Zr alloys

\begin{tabular}{cccc|} 
Casting process & As-cast $(\mu \mathrm{m})$ & T4 $(\mu \mathrm{m})$ & T6 $(\mu \mathrm{m})$ \\
\hline $\begin{array}{c}\text { Sand casting } \\
\begin{array}{c}\text { Permanent mold } \\
\text { casting }\end{array}\end{array}$ & 50 & 68 & 75 \\
\hline 17$]$ & 37 & 59 & 67 \\
\hline
\end{tabular}

\subsection{Corrosion tests}

The weight loss rates of low-pressure sand cast Mg-10Gd$3 \mathrm{Y}-0.5 \mathrm{Zr}$ alloys and metal cast alloys in as-cast, T4 and T6 conditions under immersion test are displayed in Fig. 4. The results show that the alloy at as-cast condition has the higher weight loss rate (i.e. corrosion rate) than the T4 and T6 conditions, and the corrosion rate of T4 sample is the smallest. Both sand casting and permanent mold casting processes have the same order of corrosion rates as follows: as cast $>\mathrm{T} 6>\mathrm{T} 4$. Considering the discussion in section 2.1, the different grain sizes and volume fraction of secondary phases in sand casting and permanent mold casting lead to the difference of the corrosion resistance in the same heat treatment condition, though the

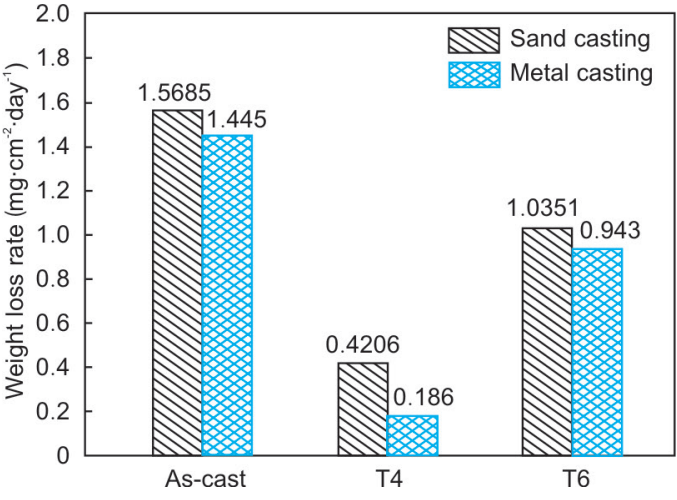

Fig. 4: Weight loss rates of sand-cast and metal-cast ${ }^{[17]}$ alloys in as-cast, T4 and T6 conditions under immersion test

microstructures are basically the same.

Figure 5 shows photographs of the corroded surfaces of the low-pressure sand-cast Mg-10Gd-3Y-0.5Zr alloys in three conditions before and after removal of the corrosion products in $5 \mathrm{wt} . \% \mathrm{NaCl}$ solution for 3 days. It can be observed that in the as-cast condition, a large area of homogeneous corrosion can be found, with obvious white corrosion products covered on the surface of the alloy, while the T4 sample exhibits slight average corrosion across the whole surface. The corrosion morphology of the T6 sample presents localized corrosion in the surrounding areas of the specimen (Fig. 5c). Furthermore, there are relatively noticeable corrosion pits left on the corroded surface of the as-cast and T6 samples after removal of the corrosion products (Figs. 5d and 5f), and there are no visible corrosion pits on the surface of the T4 sample. The visual severity of corrosion is generally in agreement with the weight loss rate shown in Fig. 4. 


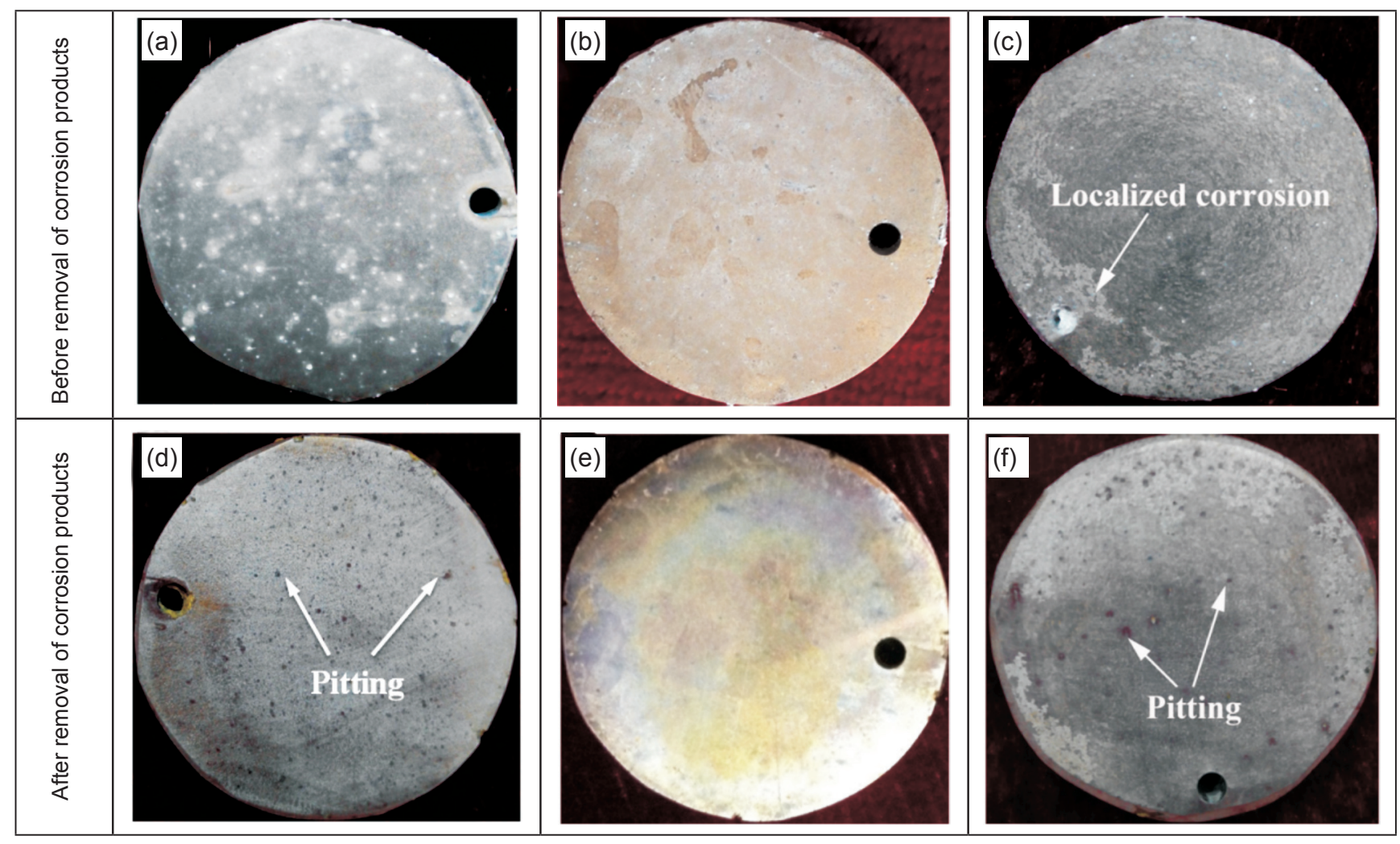

Fig. 5: Corroded surface photographs of Mg-10Gd-3Y-0.5Zr alloys before and after removal of corrosion products: (a, d) as-cast, (b, e) T4, and (c, f) T6

The morphologies of the corroded surface after removal of corrosion products in three conditions are shown in Fig. 6. As is seen from Fig. 6(a, b and c), the as-cast and T6 samples have serious and deep corroded area, while the T4 condition has slight corrosion with a small quantity of remaining eutectic compounds $\left(\mathrm{Mg}_{24}(\mathrm{Gd}, \mathrm{Y})_{5}\right)$ in local areas, and also visible $\mathrm{Zr}$-rich cores are remained. It can be concluded that the secondary phase $\left(\mathrm{Mg}_{24}(\mathrm{Gd}, \mathrm{Y})_{5}\right)$ and $\mathrm{Zr}$-rich cores have more positive corrosion potentials than that of the $\alpha-\mathrm{Mg}$ matrix. $\mathrm{Mg}_{24}(\mathrm{Gd}, \mathrm{Y})_{5}$ phase and $\mathrm{Zr}$-rich cores act as the cathodes and the $\alpha-\mathrm{Mg}$ matrix acts as the anode. Therefore, micro-galvanic corrosion in the as-cast condition inevitably occured in the matrix next to the eutectic compounds or Zr-rich cores, leading to the higher corrosion rate in the as-cast condition than that of T4 and T6 conditions. The lowest corrosion rate of the T4 sample is attributed to the dissolution of Gd, Y into the matrix, forming a supersaturated solid solution with high concentration of rare earth, which is consistent with the previous studies ${ }^{[16,17]}$. Furthermore, the corrosion of the T6 sample is more serious than that of the T4 sample because of the numerous precipitation of $\beta^{\prime}$ phase $\mathrm{Mg}_{5}(\mathrm{Gd}, \mathrm{Y})$ in the aging treatment process. Corrosion easily occurs from the nearest periphery of noble secondary phase particles to other places and the noble secondary phase particles will strongly influence the distribution of pitting ${ }^{[18]}$. As the noble secondary phase particles ( $\beta^{\prime}$ phase) precipitate in quantity in the T6 condition, they can serve as efficient cathodes and cause micro-galvanic corrosion between the $\beta^{\prime}$ phase and the matrix, resulting in the pitting corrosion (Fig. 6c). In addition, the cuboid-shaped phases were hardly corroded but the adjacent matrix was seriously corroded (Fig. 6d).

Figure 7 shows the micrograph of the corrosion products formed on the surface of the specimens after immersion in $5 \mathrm{wt} . \% \mathrm{NaCl}$ solution for 3 days. It can be observed that the more serious corrosion takes place on the surface of the as-cast specimen, with clear cracks appearing, while the T4 and T6 samples present relatively slighter corrosion (Fig. 7a-c). The similar corrosion products on the specimen surface in the three different heat treatment conditions consist of lots of tiny erect flakes (Fig. 7d-f) perpendicular to the alloy surface. The phase constituent of these corrosion products was identified by X-ray diffraction after about 20 days due to the slowly deposited powder of the corrosion products (Fig. 8). The results of XRD analysis show that the constituent of corrosion products in the three conditions is determined to be primarily $\mathrm{Mg}(\mathrm{OH})_{2}$ phase, and there are no chlorides found in the corrosion products after rinsing thoroughly. Moreover, the corrosion film of the T4 sample is more compact than those of the ascast and T6 samples (Fig. 7d-f). The thicknesses of corrosion product layers in the as-cast, T4 and T6 samples are about 34 $\mu \mathrm{m}, 5.5 \mu \mathrm{m}$, and $25 \mu \mathrm{m}$ in Fig. 7 (g-i), respectively. The much thicker corrosion products layers in the as-cast and T6 samples are related to the serious galvanic corrosion accelerating the corrosion of the matrix. In addition, there are comparatively obvious cracks across the surface of the corrosion products of the as-cast and T6 samples in the section morphologies [Fig. 7(g-i)], whereas few noticeable cracks could be observed in the T4 condition due to the slight corrosion. 

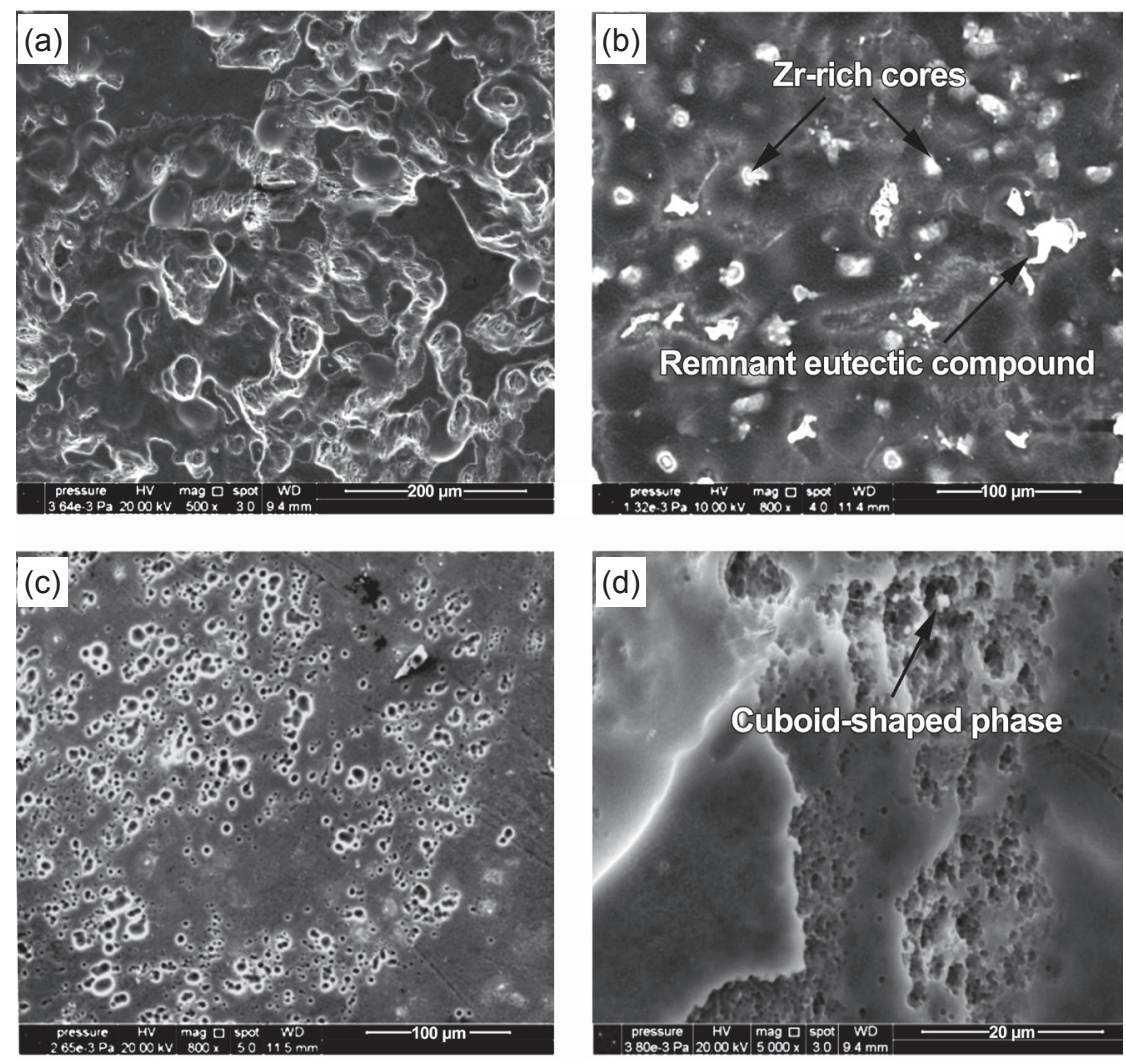

Fig. 6: Morphologies of corroded surface after removal of corrosion products: (a) as-cast, (b) T4, and (c, d) T6
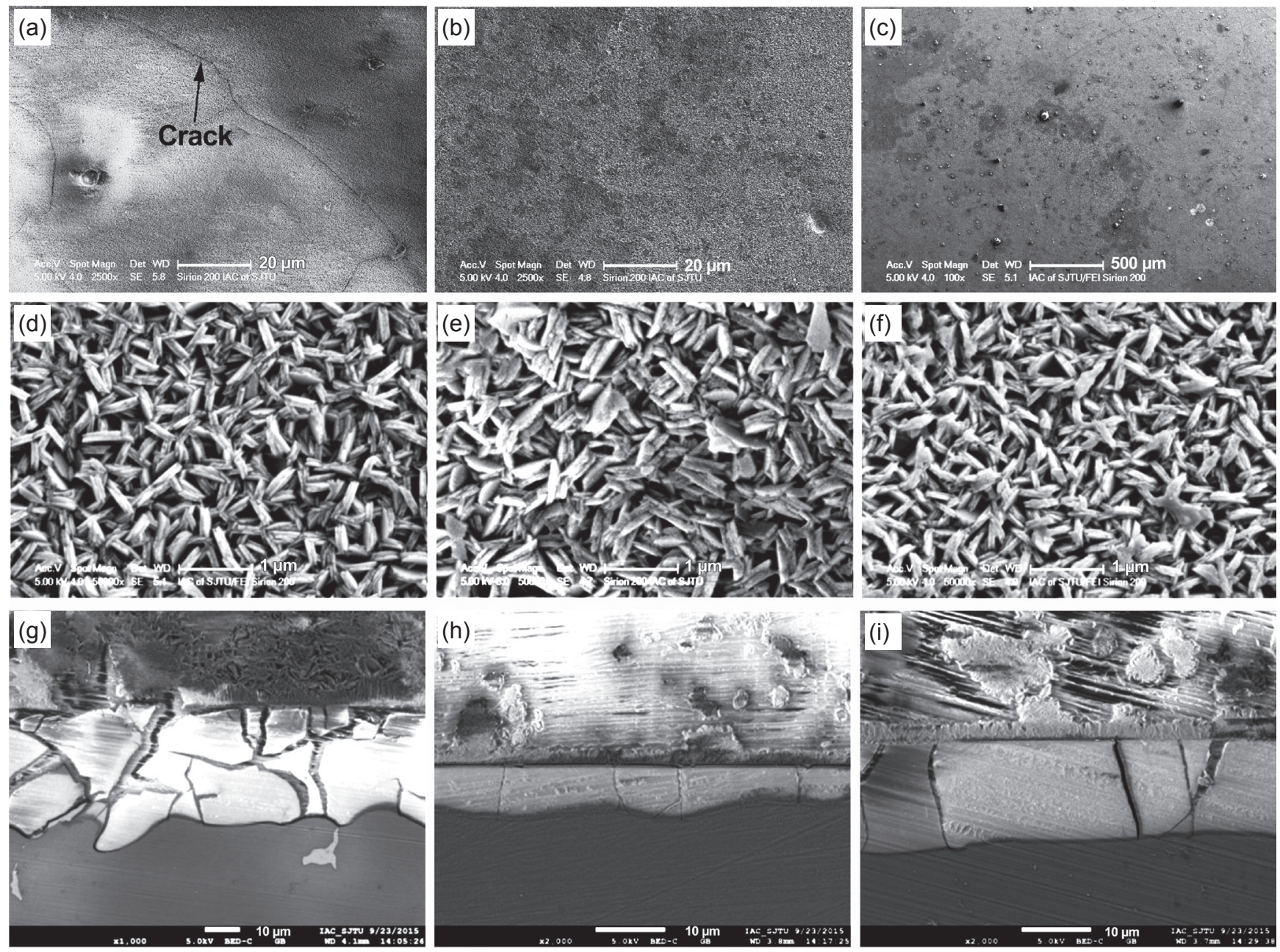

Fig. 7: Morphologies of corrosion products after immersion test for 3 days: (a, d, g) as-cast, (b, e, h) T4, (c, f, i) T6 


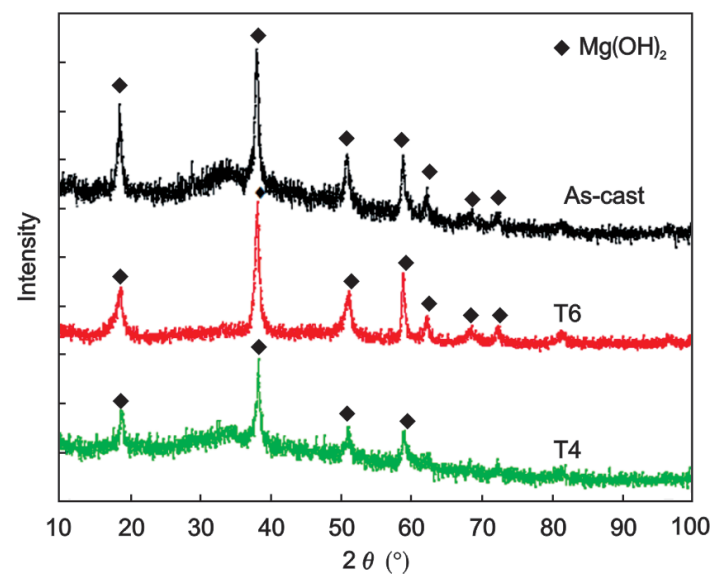

Fig. 8: X-ray difffraction patterns of corroded surface of Mg-10Gd-3Y-0.5Zr alloys

\subsection{Electrochemical measurements}

\subsubsection{Electrochemical impedance spectroscopy (EIS)}

The results of the electrochemical impedance spectra are shown in Fig. 9a. EIS measurement is an effective method to analyze the corrosion behaviour ${ }^{[19-21]}$. Each Nyquist diagram of the three conditions is characterized by two capacitive loops, and the small incomplete loop is depressed to some degree. Referring to the previous studies ${ }^{[22,23]}$, the high-frequency capacitive loops appear to be caused by both charge transfer process and formation of corrosion products film; while the mediumfrequency capacitive loops are attributed to the relaxation of mass transport in the solid phase and disappear after a long immersion time. The electrochemical impedance spectra for the alloys in as-cast, T4, and T6 conditions are similar except for the different diameters of the loops. This means that the corrosion mechanisms in the three conditions are similar, but the corrosion rates are different. The relationship between the experimental data and simulated data achieved by the proposed equivalent circuit $\left[\mathrm{R}_{\mathrm{s}}\left(\mathrm{CPE}_{1}\left(\mathrm{R}_{\mathrm{t}}\left(\mathrm{R}_{\mathrm{f}} \mathrm{CPE} \mathrm{E}_{2}\right)\right)\right]\right.$ using Zview software is shown in Fig. 9b. The well matching curves between them will be the direct evidence of the judgment about the corrosion mechanism in the EIS measurement. In other words, there are two loops of the high-frequency captance and the medium-

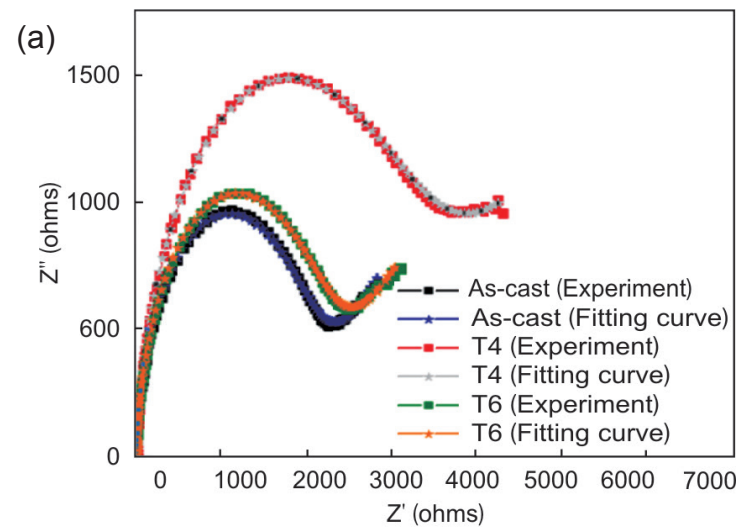

(b)

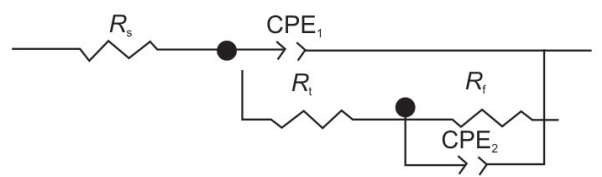

Fig. 9: (a) Nyquist plots and fitted curves for Mg-10Gd-3Y$0.5 \mathrm{Zr}$ alloys in three conditions; (b) equivalent circuit model developed to fit EIS measurements

frequency captance but without inductive loops, which shows that the low-pressure sand-cast Mg-10Gd-3Y-0.5Zr alloy has a higher resistance to pitting corrosion in different heat treatment conditions. Brett et al. ${ }^{[24]}$ also found that the pitting formation leads to the inductive loop in the impedance spectra. According to the studies of Makar and Kruger ${ }^{[25]}$, Cao Chu'nan ${ }^{[26]}$, and Song G. et al. ${ }^{[27]}$, the bigger high-frequency capacitive loops are related to the better corrosion resistance. Namely, the corrosion resistance sequence in as-cast, T4 and T6 conditions can be listed in the order as follows: T4>T6>as-cast. The result is in agreement with that of the immersion test.

In the circuit model (Fig. 9b), $R_{\mathrm{s}}$ represents the resistance of solution, $R_{\mathrm{t}}$ represents charge transfer resistance, $R_{\mathrm{f}}$ is the film resistance, $\mathrm{CPE}_{1}$ and $\mathrm{CPE}_{2}$ are constant phase elements ${ }^{[26]}$. The fitting results of the elements in the equivalent circuit obtained by Zview are shown in Table 2. The corrosion resistance can be deduced from the $R_{\mathrm{t}}$ and $R_{\mathrm{f}}$ values, indicating the preferable corrosion resistance in the T4 condition compared to the other conditions.

Table 2: Fitting results of equivalent circuit elements

$\begin{array}{cccccccc}\text { Alloys } & R_{\mathrm{s}}(\Omega) & \begin{array}{c}\mathrm{CPE}_{1-\mathrm{T}} \\ \left(\Omega^{-1} \cdot \mathrm{cm}^{-2} \cdot \mathrm{s}^{-\mathrm{n}}\right)\end{array} & \begin{array}{c}\mathrm{CPE}_{1-\mathrm{P}} \\ \left(\Omega^{-1} \cdot \mathrm{cm}^{-2} \cdot \mathrm{s}^{-\mathrm{n}}\right)\end{array} & R_{\mathrm{t}}(\Omega) & R_{\mathrm{f}}(\Omega) & \begin{array}{c}\mathrm{CPE}_{2-\mathrm{T}} \\ \left(\Omega^{-1} \cdot \mathrm{cm}^{-2} \cdot \mathrm{s}^{-n}\right)\end{array} & \begin{array}{c}\mathrm{CPE}_{2-\mathrm{P}} \\ \left(\Omega^{-1} \cdot \mathrm{cm}^{-2} \cdot \mathrm{s}^{-n}\right)\end{array} \\ \text { As-cast } & 9.031 & 1.1291 \mathrm{E}-5 & 0.94346 & 2,026 & 20,126 & 0.00093212 & 0.39383 \\ \text { T4 } & 17.27 & 1.4912 \mathrm{E}-5 & 0.94623 & 2,406 & 4.457 \mathrm{E}+8 & 0.00054809 & 0.26451 \\ \text { T6 } & 6.906 & 1.1377 \mathrm{E}-5 & 0.94437 & 1,862 & 2.609 \mathrm{E}+8 & 0.0010168 & 0.37157\end{array}$

\subsubsection{Potentio-dynamic polarization}

The potentio-dynamic polarization curves of specimens measured in $5 \mathrm{wt} . \% \mathrm{NaCl}$ solution saturated with $\mathrm{Mg}(\mathrm{OH})_{2}$ after immersion for 3,600 s are shown in Fig. 10. Table 3 lists the values of the $E_{\text {corr }}, I_{\text {corr }}, \beta_{\mathrm{a}}, \beta_{\mathrm{c}}$ according to the Tafel extrapolation for the tested alloys in the three conditions. The cathodic parts of the polarization curves represent the hydrogen evolution reactions (1), while the anodic parts of the curves represent the dissolution reactions of the magnesium alloys (2):

$$
\begin{aligned}
& 2 \mathrm{H}_{2} \mathrm{O}+2 \mathrm{e} \rightarrow \mathrm{H}_{2}+2 \mathrm{OH}^{-} \\
& \mathrm{Mg}-2 \mathrm{e} \rightarrow \mathrm{Mg}^{2+}
\end{aligned}
$$

Moreover, the polarization curves for as-cast, T4 and T6 conditions are not symmetrical between the cathodic and anodic branches. The cathodic Tafel slopes are similar for the three 


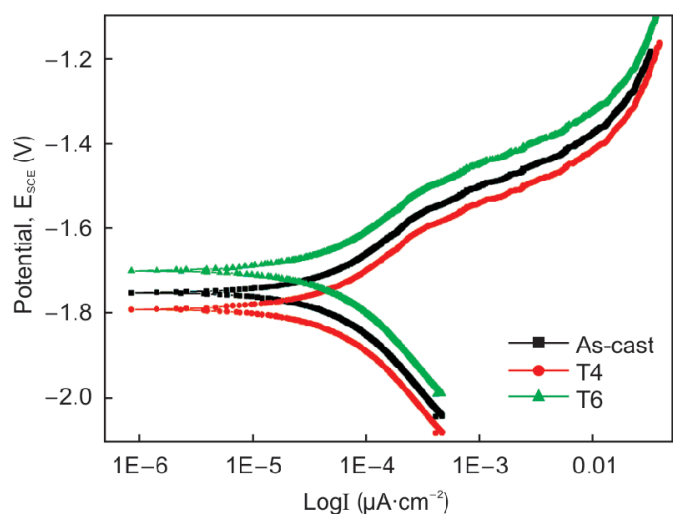

Fig. 10: Polarization curves of tested alloys in three conditions

Table 3: $E_{\text {corry }} I_{\text {corr, }} \beta_{\mathrm{a}}, \beta_{\mathrm{c}}$ values for sand-cast alloys in as-cast, T4, T6 conditions, evaluated from polarization curves measured in $5 \mathrm{wt} . \% \mathrm{NaCl}$ solution saturated with $\mathrm{Mg}(\mathrm{OH})_{2}$

\begin{tabular}{ccccc} 
Alloys & $E_{\text {corr }}(\mathrm{V})$ & $\boldsymbol{I}_{\text {corr }}\left(\mu \mathrm{A} \cdot \mathrm{cm}^{-2}\right)$ & $\boldsymbol{\beta}_{\mathrm{a}}(\mathrm{V})$ & $\boldsymbol{\beta}_{\mathrm{c}}(\mathrm{V})$ \\
As-cast & -1.753 & 36 & 0.199 & 0.222 \\
T4 & -1.789 & 10 & 0.205 & 0.185 \\
T6 & -1.698 & 33 & 0.188 & 0.220 \\
\hline
\end{tabular}

conditions, indicating the similar electrochemical reactions for hydrogen evolution, but the cathodic polarization current densities of hydrogen evolution reaction are different. The polarization curves show that both the as-cast and $\mathrm{T} 6$ conditions have positive corrosion potentials, while the corrosion potential of the T4 sample is negative. This indicates that corrosion potentials of the secondary phases in the as-cast and T6 samples are higher than that of the matrix and lead to an increase in corrosion potentials of the alloys, because the potential of an alloy is determined by the potential of the constituent phases and the area fraction covered by each phase ${ }^{[24]}$. According to the values measured by the Tafel extrapolation of the polarization curves, the corrosion current densities $\left(I_{\text {corr }}\right)$ for the three conditions are $36 \mu \mathrm{A} \cdot \mathrm{cm}^{-2}, 10 \mu \mathrm{A} \cdot \mathrm{cm}^{-2}$ and 33 $\mu \mathrm{A} \cdot \mathrm{cm}^{-2}$. The values of $I_{\text {corr }}$ in the as-cast and T6 conditions are much closer, but the T4 condition has a lower $I_{\text {corr }}$ value. This reveals that the cathodic hydrogen evolution reaction is easier kinetically for the as-cast and T6 conditions than that of the T4 condition; which is due to the existence of various secondary phases in the as-cast and T6 conditions. However, for the specific effect of the different secondary phases on the corrosion behaviors of the as-cast and T6 specimens, we still can't come to an exact conclusion on the details, and further research is needed. According to the law of Faraday, corrosion current density is proportional to the corrosion rate. Therefore, it can be concluded that the corrosion resistance is improved after solution treatment and then deteriorated after aging treatment. In addition, the anodic parts of the polarization curves reveal the existence of un-conspicuous knee points, which indicate that there is no obvious pitting appearance on the surface of the specimens during the time of the electrochemical tests.

\section{Conclusions}

The corrosion behaviors of the low-pressure sand cast and permanent mold cast Mg-10Gd-3Y-0.5Zr (wt.\%) alloys in as-cast, $\mathrm{T} 4$ and $\mathrm{T} 6$ conditions were investigated in $5 \% \mathrm{NaCl}$ solution saturated with $\mathrm{Mg}(\mathrm{OH})_{2}$. The following conclusions can be drawn:

(1) The corrosion rates have the same order of as-cast $>$ T6 $>$ T4 in both sand cast and permanent mold cast alloys. The corrosion resistance of the permanent mold casting is superior to the sand casting for the critical effect of the grain sizes as well as the volume fraction of secondary phases for the different cooling rates. Microstructure constituents have a remarkable influence on the corrosion behaviors of the low-pressure sand-cast $\mathrm{Mg}$ $10 \mathrm{Gd}-3 \mathrm{Y}-0.5 \mathrm{Zr}$ alloys in the three different heat treatment conditions.

(2) The immersion test results of the corroded surface reveal that the T4 sample exhibits less corrosion than the as-cast and T6 samples. The severe corrosion behaviors of the ascast and T6 samples are correlated with the micro-galvanic corrosion between the secondary phases and the matrix. The preferable corrosion resistance of the T4 sample is attributed to the dissolution of the eutectic into the matrix, resulting in weakening the occurrence of corrosion.

(3) The electrochemical measurements present the sequence of corrosion resistance in agreement with the immersion test. The corrosion current densities for the three conditions are 36, 10 and $33 \mu \mathrm{A} \cdot \mathrm{cm}^{-2}$, respectively. The proposed equivalent circuit $\left[\mathrm{R}_{\mathrm{s}}\left(\mathrm{CPE}_{1}\left(\mathrm{R}_{\mathrm{t}}\left(\mathrm{R}_{\mathrm{f}} \mathrm{CPE} \mathrm{E}_{2}\right)\right)\right]\right.$ by Zview software matches well with the tested electrochemical impedance spectra (EIS) data.

\section{References}

[1] Li J P, Yang Z, Liu T, et al. Microstructures of extruded Mg$12 \mathrm{Gd}-1 \mathrm{Zn}-0.5 \mathrm{Zr}$ and $\mathrm{Mg}-12 \mathrm{Gd}-4 \mathrm{Y}-1 \mathrm{Zn}-0.5 \mathrm{Zr}$ alloys. Scripta Materialia, 2007, 56: 137-140.

[2] Fu Penghuai, Peng Liming, Jiang Haiyan, et al. Fracture behavior and mechanical properties of Mg- $4 \mathrm{Y}-2 \mathrm{Nd}-1 \mathrm{Gd}-0.4 \mathrm{Zr}$ (wt.\%) alloy at room temperature. Materials Science and Engineering A, 2008, 486: 572-579.

[3] Pardo A, Merino M C, Coy A E, et al. Corrosion behaviour of magnesium/ aluminium alloys in $3.5 \mathrm{wt} \% \mathrm{NaCl}$. Corrosion Science, 2008, 50: 823-834.

[4] Liu Xianbin, Shan Dayong, Song Yingwei, et al. Influence of casting module on corrosion behavior of Mg-11Gd-3Y alloy. Transactions of Nonferrous Metals Society of China, 2011, 21: 903-911.

[5] Gao Lei, Chen Rongshi, Han Enhou. Enhancement of ductility in high strength Mg-Gd-Y-Zr alloy. Transactions of Nonferrous Metals Society of China, 2011, 21: 863-868.

[6] Sun Ming, Wu Guohua, Wang Wei, et al. Effect of Zr on the microstructure, mechanical properties and corrosion resistance of Mg-10Gd-3Y magnesium alloy. Materials Science and Engineering A, 2009, 523: 145-151.

[7] Liu W C, Dong J, Zhang P, et al. Improvement of fatigue properties by shot peening for Mg-10Gd-3Y alloys under different conditions. Materials Science and Engineering A, 2011, 528: 5935-5944. 
[8] Pang Song, Wu Guohua, Liu Wencai, et al. Effect of cooling rate on the microstructure and mechanical properties of sandcasting Mg-10Gd-3Y-0.5Zr magnesium alloy. Materials Science and Engineering A, 2013, 562: 152-160.

[9] Edler F J, Lagrené $G$ and Siepe R. Thin-walled Mg structural parts by a low-pressure sand casting process. In Magnesium Alloys and Their Applications. K U Kainered, WILEY-VCH Verlag GmbH: Weinheim, 2000, 553-557.

[10] Wang Qilong and Wu Guohua. Study on the microstructure and mechanical properties of sand mould cast Mg-10Gd3Y-Zr alloy. Master's Thesis, Shanghai: Shanghai Jiao Tong University, 2010: 29-35. (In Chinese)

[11] Jiang Longkang, Liu Wencai, Wu Guohua, et al. Effect of chemical composition on the microstructure, tensile properties and fatigue behavior of sand-cast Mg-Gd-Y-Zr alloy. Materials Science and Engineering A, 2014, 612: 293-301.

[12] Chang Jianwei, Guo Xingwu, He Shangming, et al. Investigation of the corrosion for Mg- $x \mathrm{Gd}-3 \mathrm{Y}-0.4 \mathrm{Zr}(x=6$, $8,10,12$ wt.\%) alloys in a peak-aged condition. Corrosion Science, 2008, 50: 166-177.

[13] Wang Wei, Wu Guohua, Wang Qudong, et al. Gd contents, mechanical and corrosion properties of Mg-10Gd-3Y-0.5Zr alloy purified by fluxes containing $\mathrm{GdCl}_{3}$ additions. Materials Science and Engineering A, 2009, 507: 207-214.

[14] He S M, Zeng X Q, Peng L M, et al. Precipitation in a Mg-10Gd$3 \mathrm{Y}-0.4 \mathrm{Zr}$ (wt.\%) alloy during isothermal ageing at $250{ }^{\circ} \mathrm{C}$. J. Alloys Compd., 2006, 421: 309-313

[15] Cao Liang, Liu Wencai, Li Zhongquan, et al. Effect of heat treatment on microstructures and mechanical properties of sand-cast Mg-10Gd-3Y-0.5Zr magnesium alloy. Transactions of Nonferrous Metals Society of China, 2014, 24: 611-618.

[16] Kiryuu M, Okumura H, Kamado S, et al. Corrosion resistance of heat resistant magnesium alloys containing heavy rare earth elements. Journal of Japan Institute of Light Metals, 1996, 46: 39-44.

[17] Peng Liming, Chang Jianwei, Guo Xingwu, et al. Influence of heat treatment and microstructure on the corrosion of magnesium alloy Mg-10Gd-3Y-0.4Zr. Journal of Applied Electrochemistry, 2009, 39: 913-920.

[18] Guo Xingwu, Chang Jianwei, He Shangming, et al. Investigation of corrosion behaviors of Mg- $6 \mathrm{Gd}-3 \mathrm{Y}-0.4 \mathrm{Zr}$ alloy in $\mathrm{NaCl}$ aqueous solutions. Electrochimica Acta, 2007, 52: 2570-2579.

[19] Pebere N, Riera C, and Dabosi F. Investigation of magnesium corrosion in aerated sodium sulfate solution by electrochemical impedance spectroscopy. Electrochimica Acta, 1990, 35: 555561.

[20] Baril G and Pebere N. The corrosion of pure magnesium in aerated and deaerated sodium sulphate solutions. Corrosion Science, 2001, 43: 471-484.

[21] Baril Geneviève, Blanc Christine, and Pébère Nadine. AC Impedance Spectroscopy in Characterizing Time-Dependent Corrosion of AZ91 and AM50 Magnesium Alloys. Journal of the Electrochemical Society, 2001, 148: B489-496.

[22] Morlidgea J R, Skeldon P, Thompson G E, et al. Gel formation and the efficiency of anodic film growth on aluminium. Electrochimica Acta, 1999, 44(14): 2423-2435.

[23] Song $G$ and Atrens A. Understanding Magnesium Corrosion - A Framework for Improved Alloy Performance. Advanced Engineering Materials, 2003, 5: 837-858.

[24] Brett C M A, Dias L, Trindadem B, et al. Characterisation by EIS of ternary $\mathrm{Mg}$ alloys synthesized by mechanical alloying. Electrochimica Acta, 2006, 51: 1752-1760.

[25] Makar G L and Kruger J. Corrosion Studies of Rapidly Solidified Magnesium Alloys. Journal of the Electrochemical Society, 1990, 137: 414-421.

[26] Cao Chu'nan. On the impedance plane displays for irreversible electrode reactions based on the stability conditions of the steady-state-I. One state variable besides electrode potential. Electrochimica Acta. 1990, 35: 831-836.

[27] Song G, Atrens A, St John D, et al. The anodic dissolution of magnesium in chloride and sulphate solutions. Corros. Sci., 1997, 39: 1981-2004. 